\title{
PROPOSITAL E PROPOSITALMENTE
}

\author{
José de Sá Nunes \\ Doutor em Filologia Portuguesa
}

"Li, meu caro amigo, num dos registros do nosso querido "Jornal do Comércio" uma nota que me fez pensar: se o topónimo "Sacopã" deve ser escrito com "an" ou "ã"; e se se deve dar preferência a "proposital" ou "propositado". E o próprio registrador gravou lá este período: "Não o fizemos propositadamente (Protesto! escreva "propositalmente", já está uma voz a clamar). "Ora, como também eu me acho na mesma situação do registrador, assentei de o consultar acerca dessas duas coisas: é "Sacopan" ou "Sacopã"? E por quê? Deve-se dizer "proposital" ou "propositado"? Qual a razão da escolha? E, portanto, "propositalmente" ou "propositadamente"? Espero ler a resposta, pela qual the saberei agradecer, em qualquer das suas revistas predilectas.

L. F. J."

Sacopã.

Quanto a "Sacopã", desde que foi oficializada a ortografia portuguesa em 15 de Fevereiro de 1911, ficou definitivamente assentado que a grafia da vogal nasal "ã" em fim de palavra fosse com til, e não com "n". Essa norma conservou-se no Acordo de 1931, no sistema de 1943 e no Acordo de 1945. Conseguintemente, a grafia exacta do topónimo carioca é "Sacopã". A forma primitiva era "Socopenupã", que se reduziu a "Socopã", hoje "Sacopã", e significa "pancada nos socós". Assim se chamava a lagoa de Rodrigo de Freitas. Hoje designa uma estrada e rua na Gávea.

Respectivamente a "proposital", "propositado" e os seus derivados em "mente", esta é a terceira vez que respondo a 
consultas análogas. A primeira foi a 25 de Abril de 1935, publicada na revista porto-alegrense "O Eco", do Colégio Anchieta, número de 30 de Agosto daquele ano, a págs. 275-276; a segunda foi a 22 de Agosto de 1944, em carta endereçada ao Sr. Osni Botticelli, residente na Capital Federal. Agora, utilizando novos argumentos, fornecidos pela observação de quase quatro lustros, vou responder a quem usa o criptónimo L.F.J., mas vou responder largamente, para corresponder à sua confiança em mim depositada e à de dois outros consulentes que esperam pelo meu parecer.

A Lição de Rui Barbosa.

No Brasil, surgiu a questão da vernaculidade de tais expressōes na ocasiāo em que Rui Barbosa apresentou ao Senado o seu parecer sobre a redacção do projecto do Código Civil, em 3 de Abril de 1902. Foi o caso que, estando assim redigido o inciso III do art. 46 do projecto - "Tudo quanto no imóvel o proprietário mantiver propositalmente,...." - o grande jurisconsulto comentou: "Propositalmente não é português. As regras da analogia não autorizam a formação de semelhante neologismo. Temos, em seu lugar, uma dúzia de advérbios e locuções adverbiais: de propósito, PROPOSITADAMENTE, de intenção, de intuito, intencionalmente, de indústria, de plano, adrede, acinte, acintemente, determinadamente, sobrepensado (adv.), pensadamente, de caso pensado, premeditadamente, deliberadamente. De propósito fizemos propositadamente, de a propósito compusemos apropositadamente. Ninguém diz apropositalmente. Das palavras em ósito (apósito, compósito, depósito, repósito) não se extraiu advérbio em ente. Agora, de propósito cunham proposital, que se adverbiou em propositalmente. Mas ninguém ainda se atreveu a dizer aproposital, e muito menos aposital, composital, deposital, reposital. Assim como de a propósito só se pôde fazer apropositado e apropositadamente, também de propósito o uso vernáculo só adjectivou propositado, e adverbiou propositadamente. São as expressões consagradas nos autores e nos vocabulários. Como, pois, legitimar proposital e propositalmente? De outro lado, para que essas duas palavras, tão contestáveis, quando 


\section{$-155-$}

temos, com o mesmo sentido e quase a mesma forma, PROPOSITADO e PROPOSITADAMENTE?" ("Parecer sobre a Redacção do Projecto da Câmara dos Deputados", edição de 1902, pág. 54.)

Estava assim redigido o art. 96 do projecto: "Nos actos bilaterais o silêncio proposital de uma das partes...." $O$ Mestre do Direito e do Vernáculo não deixou de vir com a emenda: "Proposital. Diga-se: intencional, voluntário, deliberado." (Op. cit., pág. 70.)

Rui Barbosa e Carneiro Ribeiro.

Após da revisão de Rui, foi o projecto às mãos do Prof. Dr. Ernesto Carneiro Ribeiro, que deu razão ao seu ex-aluno, mas fez a seguinte observação: "Não é de propósito nem de a propósito que se compõem em nossa língua os advérbios propositadamente, apropositadamente; mas dos adjectivos propositado, apropositado, em suas terminações femininas, ajuntando-se-lhes o sufixo mente (e não ente), derivado do ablativo latino mente, que, nos idiomas novo-latinos, de elemento autónomo que era, se transformou em sufixo ou elemento formativo." ("Ligeiras Observações", 1902, pág. 22.)

Na sua "Réplica" diz Rui Barbosa: "Dá-me razão aqui o Dr. Carneiro. Reconhece que propositalmente não tem carta de palavra portuguesa. Por me não sair de graça, porém, a vantagem, confessando que se descuidara de trocar o propositalmente em intencionalmente, põe o Dr. Carneiro esta ressalva: "Não por ser aquele vocábulo de formação nova, senão por não ser abonada a sua analogia". (Edição de 1904, n. 192, pág. 142.)

Adiante, ainda respeito ao "proposital" e ao "propositalmente", escreve o Dr. Rui: "Confessa o autor da Resposta não encontrar esses vocábulos em dicionário nenhum. Mas a eles se aferra; porque João Ribeiro (Gram., pág. 298) os enumera entre os adoptados pelo uso geral. Entretanto, o único registo autêntico do uso geral é a prática dos bons escritores." E conclui: "Ora por que, a não ser um capricho aberrativo, a força de uma perversão, ou o gosto de errar, trocaremos em propo- 
sital o vernáculo propositado e em propositalmente o vernáculo propositadamente?" (Ibidem, págs. 476-477.)

E na pág. 572: "As novidades que refuguei, não passam de meia dúzia, e não as refuguei porque novidades, mas porque desnecessárias e bastardas: PROPOSITALMENTE, honorabilidade, agir, desvirginar, afectar, autoral."

$\mathrm{Na}$ "Tréplica afirma o Dr. Carneiro que deu razão ao Dr. Rui por haver reprovado o "propositalmente", mas censurou-o por ter dito que "de propósito fizemos propositadamente", pois o advérbio não se forma do substantivo, e sim do adjectivo "propositado" em sua terminação feminina, ajuntando-se-lhe o sufixo "mente". (Cf. a "A Redacção do Projecto do Código Civil e a Réplica do Dr. Rui Barbosa", edição de 1923, pág. 85.)

Não foi Rui quem formou o vocábulo.

Desde já cumpre desfazer uma inexactidão que muitos consideram verdade: nāo foi Rui Barbosa quem primeiro formou o advérbio "propositadamente"; ele o recebeu de Cândido de Figueiredo, e por influência da lição deste foi que se arvorou em defensor de "propositado" e "propositadamente". Quem quiser convencer-se disso abra a "Réplica" e leia os números 379 e 380 (págs. 476 e 477 da edição de 1904): aí, aludindo ao vocábulo "proposital", escreveu isto: "A respeito desta novidade $C$. de Figueiredo se pronuncia nestes termos: "O termo proposital nunca se me deparou em escritor português. E para que se há-de ele inventar, se propositado exprime a mesma ideia, tem derivação conforme à índole do nosso idioma, e é usado pelos que bem falam?" (Lições Prát., v. III, pág. 44.) - "Propositadamente, diz C. de Figueiredo (Liç. Prát., v. II, pág. 229), e D. Michaëlis de Vasconcelos na sua tradução da grande obra de Storck sobre a Vida e Obras de Luís de Camões." Sejamos brasilistas, mas alumiados pela verdade e pela justiça.

Na verdade, foi Cândido de Figueiredo quem, no ano de 1899, disse que "acto proposital" era "audacíssimo", e acrescentou aquilo que Rui transcreveu das "Liçōes Práticas", vol. III, pág. 44 (na 5a. ed., pág. 41). Depois, no seu "Vade-mécum", 
à pág. 246 (2a. ed.), estigmatizou o "proposital" com o epíteto de "asneira". Mas o vocábulo já existia na Língua, como existiam "apropositadamente" e "despropositadamente", que ao diante se verão.

Vejamos o que respeito a isso tem escrito um dos nossos consumados filólogos.

\section{Opinião de Said Ali.}

Nas "Dificuldades da Língua Portuguesa" destarte se manifesta: "O argumento da exuberância de expressões indígenas de antigo cunho falha muitas vezes; e contudo certos dizeres novos, realmente práticos, são tão mal vistos que o escritor castiço, em os topando, se persigna escandalizado como o cristão devoto em face do inimigo. Um desses horrores é o termo proposital, substituindo, algumas vezes, o já um tanto obsoleto acintoso, e criado por influência do antiquíssimo can sual. Como o povo fala sem primeiro ler os cinco volumes da "Nova Floresta" e os quinze volumes dos "Sermões", inventa muito naturalmente por analogia, por associação de ideias um tiro proposital ao lado de um tiro casual; o que sem dúvida é mais sumário e mais conciso do que o tiro disparado de propósito. Os puristas, votando pela concisão, mas supondo que assim se envenena a Língua, acharam já a triaga no termo propositado, produto de pouca habilidade, desconhecido de Camões e cuja semente não consta andar espalhada pela "Nova Floresta" ou pelos livros de Vieira. Com o tempo e a decisão da maioria vencem-se repugnâncias linguísticas as mais justas. Se proposital e propositado não morrerem ambos, não será de admirar que venha a prevalecer justamente o termo menos recomendável ou menos recomendado agora." (Págs. 309 e 310 da 2.a edição.)

$\mathrm{Na}$ "Gramática Secundária da Língua Portuguesa" (pág. 307) ele tacha de duplo preciosismo" a substituição de proposital, propositalmente, termos vulgares, mas não documentados em escritor clássico, por propositado, propositadamente, que nem ocorrem nos clássicos nem são conhecidos do povo. duplo preciosismo, porque a emenda esquece de propósito, dicção antiga, correcta e corrente ainda hoje." 
E nos "Meios de Expressão e Alterações Semânticas" (edição de 1951, pág. 177) rejeita as duas formas - propositalmente e propositadamente - por desnecessárias: tanto é desnecessário o propositalmente, "plebeu de nascença", quanto o propositadamente, usado pelos "bem falantes"; e acrescenta que "à recomendação do sucedâneo propositadamente faltou um requisito essencialíssimo. Por descuido, esquecimento ou outra causa desconhecida, deixou-se de provar, de documentar a vernaculidade do curioso advérbio ou, sequer, do adjectivo propositado, que lhe teria dado origem".

\section{A Evolução do Idioma e os Clássicos.}

Aqui é que bate o ponto. Se fôssemos obrigados a empregar sòmente as palavras que se encontram nos clássicos, jamais a Língua sairia do século XVII, em que escreveram Bernardes e Vieira. Se nos fosse lícito apenas guiar-nos pelo escrever de Camilo e Castilho, Herculano e Latino Coelho, não haveria possibilidade alguma de o nosso idioma progredir e acompanhar a evolução universal. Milhares de vocábulos existem hoje nos dicionários, que eram completamente desconhecidos de Vieira e Bernardes; e, contudo, são portugueses de lei, usados pelos escritores mais primos, pelos mais consagrados poetas e por toda a gente. O "requisito essencialíssimo" exigido pelo nosso ínclito filólogo, para que "propositado" e "propositadamente" sejam dignos de figurar como vernáculos, deve considerar-se descabido e inoportuno ante as leis que os protegem e lhes concedem o direito de viverem e viçarem. Sem embargo disso, vejamos se falta o "requisito essencialíssimo" que esqueceli a Rui Barbosa e também a Carneiro Ribeiro.

Um dos primeiros clássicos da nossa língua, D. Fr. Amador Arrais, quinhentista de muito mérito pela pureza, graça e simplicidade dos seus escritos; Fr. João de Ceita, estimado clássico também quinhentista, que nos deixou vários "Sermões"; e o seiscentista Diogo de Paiva de Andrade, que nos legou obras preciosíssimas, empregaram, todos três, o adjectivo participial "apropositado"; e o quinhentista António Pinto Pereira, autor da valiosa "História da India", usou do adjecti- 
vo "desapropositado", o que, tudo, nos certifica Morais no seu "Dicionário da Língua Portuguesa", edição de 1813. De Fr. João de Ceita copiou ele este fragmento: "Noite apropositada para a sua determinação." Mostra a expressão "digressão desapropositada" de António Pereira Pinto e apresenta mais esta: "coisas desapropositadas". Além disso, Morais consigna "despropositado" e os advérbios "apropositadamente" e "despropositadamente". Esses registros se fizeram há quase centúria e meia. E, se Morais inseriu no seu dicionário tais advérbios e adjectivos participiais, foi porque os encontrou em bons autores que o precederam.

\section{A Analogia.}

Ora, se existem "apropositado" e "desapropositado" com o "requisito essencialíssimo" exigido por Said Ali, e se há os advérbios "apropositadamente" e "despropositadamente" inscritos em léxico da nossa língua há século e meio, por que não há-de haver também "propositado" e "propositadamente", formados à imagem e semelhança daqueles? Todos têm por base e origem o substantivo "propósito"; de "propósito" foi que se formou "apropositado", "despropositado" e "desapropositado", mediante prefixos e sufixos adequados, e destes, no feminino, mais o sufixo "mente", se compuseram os respectivos advérbios. Aliás, dezenas de advérbios possuímos nas mesmas condições: bastará pôr no feminino e acrescentar o sufixo "mente", para que os adjectivos-particípios que vou apontar surjam como surgiram aqueles e como surgiu "propositadamente": afectado, aquietado, arrebatado, assentado, confessado, contraditado, curvado, dispensado, entortado, escusado, estremado, extremado, falhado, inquietado, interditado, libertado, malquistado, misturado, molestado, revoltado, safado, suspeitado; acendido, agradecido, arrependido, conhecido, convencido, corrompido, desenvolvido, escolhido, escondido, estendido, pervertido, refrangido, resolvido, tolhido, torcido; abstraído, afligido, coagido, confundido, constringido, contraído, contundido, difundido, distinguido, fingido, oprimido, restringido.

Alguém me poderá objectar que não existe o verbo "propositar", donde poderia sair o "propositado". Objecção é essa 
de pouca monta para quem sabe que, havendo na Língua o verbo "apropositar", nada é mais trivial do que a sua forma aferética, do que existem numerosos exemplos, como "portuguesar", "profundar", "sinalar", etc.; e também para quem sabe que nem sempre vige 0 infinitivo cujo particípio tem vida autónoma, do que boa prova seja o "desapropositado" que Morais averbou, apesar de não saber da existência do infinitivo "desapropositar", que nem um dos nossos léxicos registra. Da vigência do particípio desse verbo tinha ciência o velho lexicógrafo, tanto que citou um par de exemplos, e o Prof. Carneiro Ribeiro não se dedignou de usá-lo nos "Serōes Gramaticais", em que ele, apontando certos vícios de linguagem, diz ser comum "entre os Fluminenses o uso desapropositado do verbo saber na terceira pessoa do singular do presente do indicativo, sem relação alguma com os elementos da frase". (V. a 4. a edição, pág. 595.)

\section{Preciosismo.}

Além de tudo, não me parece de bom aviso capitular de "preciosismo" o uso de uma forma iniludivelmente correcta em vez de outra cujos foros de vernaculidade pōem fundamentadamente em dúvida os bons conhecedores do idioma pátrio. Preciosismo seria, ao revés, o emprego de "proposital" e "propositalmente", quando existem na Língua, afora "propositado" e "propositadamente", sucedâneos capazes de vantajosamente substituí-los, como são, além dos dezessete apresentados pelo Dr. Rui Barbosa, "advertido" e "advertidamente", "acintoso" e "acintosamente", "apostado" e "apostadamente", "deliberado" e "deliberadamente", "determinado" e "determinadamente", "estudado" e "estudadamente", "reflectido" e "reflectidamente", "pensado" e "pensadamente" ou "de pensado" e também "a propósito", conforme as ocasiōes e os casos ocorrentes.

\section{Um Anglicizador.}

Não quero deixar de fixar aqui (já que falei em casos) um linguajar de certo colega meu, quando cursávamos humanidades. Ele ouvira falar do tipo do francelho petulante 
a que se refere Rui na "Réplica" ( $n .{ }^{\circ} 468$ ), francelho que "achatava" quando queria comprar, que tratava de "trupas" as tropas, que trocava bolsas em "bursas", que disfarçava os seus pensamentos em "peniseiros", que não "neglijava'i os seus deveres e, com as surpresas e graças desse fraseado, era o "sulajamento" do amo. Mas o meu colega estava estudando o inglês e, em vez de macarrònicamente afrancesar a fala, tudo anglicizava. Uma das suas formas predilectas era a terminação "al", que aplicava a torto e a direito. Se acertava de falar em matérias do curso ginasial, fazia exercício "geografical" e resolvia um problema "geometrical"; se adoecia, solicitava logo um produto "farmaceutical" e a vida para ele era uma coisa "filosofical". Não havia meio de pronunciar "propositado": o "proposital" saía-lhe da boca a todos os momentos, e acabou sendo galardoado com uma reprovação "diabolical".

\section{Proposital e Propositalmente.}

Mas, falando sério, não há duvidar de que o povo só conhece "proposital" e "propositalmente". Rui Barbosa alude à confissão do autor da "Resposta" parlamentar, de que não foram encontrados em nenhum léxico esses vocábulos, mas, apesar disso, a eles se aferra, porque João Ribeiro os enumera, na sua "Gramática", entre os adoptados pelo uso geral. " $E$, afora o próprio João Ribeiro, que daquele advérbio já usou (Hist. do Brasil, 2a. ed., pág. 10), e Júlio Ribeiro, que também lhe abriu porta (A Carne, pág. 8), não conheço um só de autoridade, que desses termos se valesse". ("Réplica", pág. 477.) $\mathrm{Na}$ edição 19a. da "Gramática Portuguesa" para o curso superior, João Ribeiro já não inclui tais vocábulos entre os adoptados pelo uso geral; mas é certo que ele empregou o advérbio na 2a. edição da sua "História do Brasil", como se vê no seguinte passo: "Propositalmente, desviou-se do rumo habitual, diz-se que para evitar as calmarias africanas". E anos depois, nas "Curiosidades Verbais" (pág. 230), reincidiu: "Fazemo-lo, propositalmente, por mostrar a probidade e fundamento da nossa crítica". 
Também o metuendo crítico literário Osório Duque Estrada, não obstante o seu nefasto rigorismo, deixou escapar isto que se lê à pág. 245 da sua "Crítica e Polémica": — "Entretanto, para evitar qualquer deturpação proposital, ....., deliberou o abaixo assinado mudar para longas algumas das sílabas breves....."

Tenho fichados outros de Raul Pompeia, Mário Bouchardet, um de Carlos de Laet e um do padre Augusto Magne. E foi por isso que, a 22 de Agosto de 1944, respondi ao distinto consulente Osni Botticelli serem abonadas por escritores modernos as palavras "proposital" e "propositalmente". Entretanto, impende-me chamar a atenção desse consultante e dos leitores para o facto muito significativo que vou expor: João Ribeiro, insigne gramático, verdadeiro filólogo, escritor primoroso, seja como historiador, seja como jornalista, foi também lexicógrafo: refundindo, acrescentando e melhorando o dicionário de Simões da Fonseca, nele introduziu lições magníficas, esparsas por toda a obra, e uma delas é esta: "PROPOSITAL. adj. Não são considerados de bom uso proposital e propositalmente; convindo antes dizer propositado e propositadamente". ("Novo Dicionário Enciclopédico Ilustrado da Língua Portuguesa", ed. de 1926, pág. 1060.)

No prefácio "Ao Leitor", pág، V dessa obra, ele próprio dá o bom exemplo: "Excluímos propositadamente desta secção os escritores vivos e quantos ainda não podem ser julgados com inteira imparcialidade". Em sua "Gramática Portuglesa", edição de 1920, pág. 352, já havia ele escrito: "O pouco que propositadamente aí dissemos....."

Os dicionários de Augusto Moreno e de Francisco Torrinha desconhecem "proposital", pois só registram "propositado". O de Jaime de Séguier consigna "propositado" e "propositadamente", seguindo os passos de Cândido de Figueiredo, que em todas as ediçōes do seu dicionário publicadas durante a sua vida averbou esse adjectivo e esse advérbio; e, inscrevendo nele as formas "deliberadamente", "de indústria", "estudadamente", "intencionalmente", aponta o significado de "propositadamente", termo que se lê também nas 
definiçōes de "acataléctico", "desencaixar" e outros. Como sinónimo de "intencional" ele apresenta "propositado", e é de "propositado" e "propositadamente" que se utiliza em suas obras. Eis algumas amostras: "Ali, o extremecimento não é casual: é propositado e sistemático....." ("Lições Práticas", Vol. II, 6.a ed., pág. 27.) - "Tomar como oiro de lei o pechisbeque que o mestre, propositadamente, ou por capricho, incrustou em muitas páginas dos seus livros admiráveis". (“O que se não Deve Dizer", vol. I, 4.a ed., pág. 227.) - "Propositadamente me abstenho de categorizar conjunções". ("O Problema da Colocação de Pronomes", 4.a ed., pág. 262.) - "Pelo conhecimento directo, que propositadamente tenho adquirido dessa linguagem, ....." ("Problemas da Linguagem", vol. I, 3a. ed., pág. 53.) - "Ele imaginaria que eu, propositadamente, lhe atribuíra o mofino comparativo..." (Ibidem, vol. III, ed. de 1923, págs. 292-293.) — "Propositadamente neguei registo a vocábulos, que tinham a abonação de Rui Barbosa e que eram do meu conhecimento!!!" ("As últimas palavras do autor sobre a quarta edição", pág. 1347 do vol. II do "Novo Dicionário da Língua Portuguesa", 6.a ed.)

Desde a 5 a. edição desse dicionário se dá guarida ao adjectivo "proposital", desrespeitando-se a disposição de última vontade do benemérito lexicógrafo. A 1 de Junho de 1922 assim escreveu ele na 3a. edição: "Naturalmente, a minha idade já me não permitirá ver outras ediçōes desta obra; mas, veja-as eu ou não, é oportuna e salutar a seguinte declaração: doendo-me de facto as torturas de que foi vítima o "Dicionário de Morais depois da 2a. edição, e desejando eu que mas não inflijam com impunidade, enjeito categòricamente as responsabilidades literárias e científicas das correcções e aditamentos, que se façam, embora excelentemente, às edições, não revistas ou dirigidas por mim, do Novo Dicionário da Língua Portuguesa. Possa esta declaração ter o valor de disposição de última vontade". (Pág. 1346 do II vol. da 6a. edição.)

Jorge Guimarães Daupiás, responsável pela organização da 5a. edição do "Novo Dicionário" de Cândido de Figueiredo, à qual se seguiu logo a 6.a (e já está na 11.a), introduziu o 
vocábulo "proposital", que Figueiredo sempre combateu por considerá-lo "asneira" "Vade-mécum dos Estudiosos da Lingua”, 2.a ed., pág. 246.)

"Asneira" é, pois, o "proposital" segundo Cândido de Figueiredo; consoante o critério de Rui Barbosa, só "um capricho aberrativo, a força de uma perversão, ou o gosto de errar" fará com que se troque em "proposital" o "propositado"; conforme a opinião do Dr. Carneiro, "proposital" não passa de "neologismo escusado"; e o "propositalmente" NÃO É PORTUGUÊS - di-lo o célebre autor da "Réplica".

\section{Exemplos de "Propositado".}

De "propositado" é que lança mão esse Mestre dos mestres, assim como os que se prezam de amar o seu idioma. Na mesma "Réplica" e na "Queda do Império" se podem ver exemplos como estes: "Sei eu lá se o erro do acento supérfluo é propositado, ....?" (N. ${ }^{\circ} 359$, pág. 457.) - "As [testemunhas] que do ocorrido nessas conferências apenas soubessem de ouvir a um, ou a outro, por mais insuspeitáveis que esses fossem de inveridicidade propositada, já não seriam testemunhas de ciência própria. ("Queda do Império", ed. de 1921, tomo I, pág. LXXV.) E, como ele, é desse adjectivo participial que se valem os mais primorosos vernaculistas. Um exemplo do eruditíssimo Pinheiro Domingues: "..... originalidade que não é propositada...." ("Revista Filológica", n. ${ }^{\circ}$ 24, pág. 357.)

Do nosso grande filólogo Sousa da Silveira: "O processo popular era espontâneo, inconsciente, fatal; cedo interveio, porém, a acção propositada e reflectida dos eruditos....." ("Trechos Selectos", 4.a ed., pág. 28.)

Do notável professor doutor José Inês Louro: “A terminada em -tia terá geralmente o exclusivo da acepção cirúrgica (ortopédica, cirúrgica, etc.), ou seja, acção provocada por processos mecânicos propositados". ("Questões de Linguagem Técnica e Geral", ed. de 1941, pág. 284.) Do eminente filólogo Rodrigo de Sá Nogueira: "E de crer que essa prosódia seja propositada....." ("Subsídios para o Est. das Conseq. da Analogia em Port.", edição de 1937, pág. 61.) 


\section{Exemplos de "Propositadamente".}

Não careceria trazer à colação documentos comprobatórios do uso deste advérbio após do que venho de explanar; mas tenho ouvido e lido que só os modernistas e brasilistas é que o empregam. Ora, já demonstrei que foi Cândido de Fìgueiredo quem influiu no espírito de Rui Barbosa a reprovação do "propositalmente" e a recomendação do "propositadamente", única forma esta por aquele usada, como se viu acima. De Rui não faltam excertos como estes: "Mas A. Herculano mui propositadamente escreveu o, tendo em mira toda a oração principal". ("Réplica", n. ${ }^{\circ} 175$, pág. 230 .) Nem carece de citar outros, visto que ele deixou para sempre escrito: "Por que, a não ser um capricho aberrativo, a força de uma perversão, ou o gosto de errar, trocaremos..... em propositalmente o vernáculo propositadamente?" (Réplica", n. ${ }^{\circ}$ 380 , pág. 477.)

Mário Barreto ministrou esta lição: "Assim de propósito exprime a mesma coisa que propositadamente (não fiz o mal de propósito).... Rui Barbosa, na sua Réplica, provou a ilegitimidade vernácula do proposital e do propositalmente. $O$ que é português é propositado e propositadamente: "O escritor não queria confessar, mais tarde, o seu casamento com Joaquina Pereira; até o ocultava propositadamente". (Alberto Pimentel, Os Amores de Camilo, pág. 72. Nos "Novíssimos Estudos da Língua Portuguesa", 2a. edição, págs. 214 e 215.)

Leite de Vasconcelos, criticando as "Lições Práticas" de Cândido de Figueiredo $\left(1 .^{\circ}\right.$ vol., ed. de 1891$)$, assim se externou: "O autor só raramente justifica o que afirma: de modo que os leitores.... ficam com o direito de duvidar dele, não que o autor fosse capaz de propositadamente os iludir....." ("Opúsculo", vol. IV, pág. 941.)

José Maria Rodrigues, na sua monumental reimpressão de "Os Lusíadas", conforme à verdadeira 1a. edição, destarte bora errónea, a palavra existe abonada por escritores modernos, e aos vocabulistas cumpre o dever de a registar, deixando a responsabilidade da sua existência aos que a criaram ou empregaram. 
se exprime na "Introdução", pág. XIII: "Simular-se-ia uma segunda ediçãc de 1572, fazendo, pela antiga, uma nova portada, que propositadamente ficasse às avessas". (Lisboa, 1921.)

- Na pág. XXV: "Observação análoga se pode fazer a respeito do Jupiter da f. 175 v., que a métrica dispensa, a não ser que o $P$. propositadamente quisesse fazer uso de uma das licenças que lhe eram reconhecidas pelos tratadistas". No seu incomparável "Estudo sobre Os Lusíadas", publicado na "Revista de Língua Portuguesa", dirigida por Laudelino Freire, não raro se depara o "propositadamente", como se vê nos seguintes lugares: "O Poeta, segundo o seu costume, tantas vezes $\mathrm{e}$ por tantas formas manifestado, quis propositadamente escrever a palavra das duas maneiras" (N.0 22, pág. 71.) - "O Poeta mui propositadamente escreve as palavras...." (Ibidem, pág. 84.) - "A ed. de Coimbra introduz no texto um "[\&]", que o poeta do Cane. propositadamente omitiu". (N.० 29, pág. 12 , n. 2.)

Na citada edição monumental de "Os Lusíadas", escreveu Jaime Cortesão na folha que antecede a "Introdução": "Propositadamente iniciamos a série com esta edição fac-simile e crítica d' Os Lusíadas".

I. Xavier Fernandes expressa-se desta maneira: "Nunca poderia ser-lhe propositadamente desagradável". ("Réplica à Defesa", na revista lusitana "A Língua Portuguesa", vol. V, fasc. VII, pág. 238.) Rodrigo de Sá Nogueira assim escreve: "Note-se que propositadamente não digo que a semelhança ou conexão etimológica pode provocar fenómenos de assimilação ou de dissimilação". " "Subsídios para o Estudo das Consequências da Analogia em Português", ed. de 1937, pág. 13.)

$\mathrm{Na}$ "Introduçãa" que escreveu para o "Vocabulário Ortográfico da Língua Portuguesa", edição de 1940, Rebelo Gonçalves deixou este período: "Se, porém, sob vários aspectos, o Vocabulário da Academia é mais rico de palavras do que qualquer dicionário ou vocabulário português, sob outros aspectos é propositadamente menos rico". (Página XIV.)

Convém saber que esse vocabulário deu entrada a "proposital", como lha deram o de 1943 e o de 1947, porque, em- 


\section{Despropositadamente e desapropositadamente.}

Já vimos que Morais consigna em seu Dicionário "apropositadamente" e "despropositadamente", os quais adscreve também Cândido de Figueiredo. Deste último se utilizou Garrett, Camilo Castelo Branco e Carneiro Ribeiro. Provas:

"A sociedade é materialista; e a literatura, que é a expressão da sociedade, é toda excessivamente e absurdamente e despropositadamente espiritualista!" (Garrett: "Viagens na Minha Terra", 6a. edição, vol. I, págs. 22-23.)

"Em 1838, dia de Natal, embebedou-se despropositadamente e saiu para a rua". (Camilo: "A Brasileira de Prazins", edição de 1882, pág. 51.)

"A vírgula quebraria despropositadamente a unidade do todo que elas constituem". (Carneiro Ribeiro: "Tréplica", edição de 1923, pág. 734.)

E, por fim, ofereço ao distinto consulente e ao leitor um "desapropositadamente" da pena de Camilo Castelo Branco: "Por que o não amaste, Ana? - perguntou de salto e desapropositadamente D. Júlla". ("Livro de Consolação", 4a. edição, pág. 197.)

Sinto que me excedi na demonstração, mas fi-lo propositadamente. E que, há muito, me azucrinam alguns correspondentes com reproches e ironias a quem usa o malsinado advérbio que venho de propugnar, e eu aguardava um ensejo, como o que me proporcionou o consulente L. F. J., para liquidar esta questão. Não seria "com palavras taxadas e avaras" que eu satisfaria o que a mim mesmo me propus. Agora, tenham a palavra os defensores da escusada neologia.

Quanto a mim, é certo que ninguém me arredará da companhia de Rui Barbosa e Carneiro Ribeiro, João Ribeiro e Mário Barreto, Leite de Vasconcelos e José Maria Rodrigues, Jaime Cortesão e Xavier Fernandes, Rebelo Gonçalves e Cândido de Figueiredo; e, nesta lustrosa companhia, e mais na de António de Morais Silva, considero-me protegido por uma fortaleza inexpugnável. 